\title{
Analyzing the Synchronization between the Financial and Business Cycles in Turkey
}

\author{
Cüneyt Akar
}

Department of Business Administration, Bandirma Onyedi Eylul University, FEAS, Bandirma-10230, Balikesir, Turkey

\begin{abstract}
The primary purpose of this study was to investigate the relationships between the financial and business cycles in Turkey. A quarterly dataset was used for the analysis that covers the period from 1998Q1 to 2014Q4. The cycles were obtained with a Hodrick-Prescott (HP) filter design. The concordance index values, cross-correlation values and Dynamic Conditional Correlation (DCC) model were used to identify the characteristics of the relationships between the financial and business cycles. The empirical results revealed that the financial and business cycles are highly synchronized in Turkey. The results also indicate that while the credit volume cycle is the leading factor of the GDP cycle, the GDP cycle leads from the BIST 100 cycle in Turkey. The last significant conclusion is that the positive and high dynamic conditional correlations between the financial and business cycles experienced a break during the 2008 global crisis.
\end{abstract}

Keywords: Business cycle, financial cycle, concordance index, DCC, Turkish economy.

\section{INTRODUCTION}

Many researchers argue that cyclical patterns exist in financial and economic series (Avouyi-Dovi and Matheron, 2005; Besomi, 2006; Christiano et al., 2010; Adrian et al., 2010; Woodfort, 2010; Egert and Sutherland, 2012; Claessens et al., 2012; Borio, 2014). Burns and Mitchell (1946) defined such cycles as an indicator of aggregate economic activity.

Debates in this area have focused on the role of financial reasons in recession problems faced by both developed and emerging economies. There are two main arguments for explaining this role. First, asset prices increase improperly to economic realities, which lead to a bubble. The explosion of this bubble leads to a decrease in investments, which narrows the financing opportunities and a recession problem arises. Second, changes in stock prices and credit conditions affect total economic activity by modifying the goods and services prices. That being said, the change in real economic activity may result from the changes in the stock prices and the credit providing behavior of the banks, because of the risk perception and risk taking incentives (Avouyi-Dovi and Matheron, 2005; Egert and Sutherland, 2012).

Turkey is an important emerging economy for many reasons. One is that after the major financial crisis in 2001, Turkey restructured its banking system and tried to form a strong financial sector. In response, Turkey

*Address correspondence to this author at the Department of Business Administration, Bandirma Onyedi Eylul University, FEAS, Bandirma-10230, Balikesir, Turkey; Tel: +90-266-738-0945; E-mail: cuneytakar78@gmail.com JEL Classification: E32, E44, G10, G15. grew stably from 2002 until 2008, when it faced the global economic crisis $(6.2 \%$ in $2002 ; 5.3 \%$ in 2003 ; $9.4 \%$ in $2004 ; 8.4 \%$ in $2005 ; 6.9 \%$ in 2006 and $4.7 \%$ in $2007)^{1}$. Following the global economic crisis, the current account deficit and the foreign debt stock rose rapidly. Hence, the most important risk for Turkey at that time was the use of portfolio investments to finance the deficit. This may have led the risk perception of foreign investors to increase, due to the aforementioned reasons. The growth rate is negatively affected by these issues (Taban, 2011). In addition to foreign investors, the risk perception of banks also increased after the global economic crisis. That being said, the total credit volume provided by the banks was practically constant until the end of 2009 , when various difficulties arose to finance new investments. Hence, an analysis of the relationship between the financial and business cycles in Turkey would be beneficial. Consequently, this paper investigates the interactions between the business and financial cycles in Turkey.

While the gross domestic product (GDP) and household consumption variables are used for business cycles, financial cycles are based on the credit volume and BIST 100 variables. As such, in this investigation, the Hodrick-Prescott filter (hereafter HP filter) is used to obtain the cyclical components of the variables. We apply the Bry and Boschan (BB) algorithm to date the turning points of the cycles and calculate the concordance index as an indicator of the accordance. The time varying correlations between the

${ }^{1}$ The growth rates were obtained from the Turkish Statistical Institute. 
business and financial cycles are analyzed with Engle's (2002) dynamic conditional correlation (DCC) model.

This study contributes to the literature by answering the following three questions: (1) How synchronized are financial and business cycles? (2) Are there any leading or lagging relationships between financial and business cycles? (3) What are the time varying (dynamic) conditional correlation paths between financial and business cycles and are there any significant breaks in the paths?

The remainder of the paper is organized as follows. Section 2 reviews the related literature. Section 3 introduces the details of the empirical methodology. Section 4 provides the data and empirical results and Section 5 concludes the paper.

\section{LITERATURE REVIEW}

Borio (2014, p.183) stated that macroeconomics without the financial cycle is like Hamlet without the Prince. This idea is not new. Fisher (1933) and Keynes (1936) investigated the interactions between macroeconomic and financial developments during the Great Depression. In recent years, Cochrane (2006), Gilchrist and Zakrajsek (2009), Adrian et al. (2010), Christiano et al. (2010), Ng (2011), Drehmann et al. (2012), Egert and Sutherland (2012), Claessens et al. (2012), Avouyi-Dovi and Matheron (2005), Borio et al. (2013), and Borio (2014) also investigated the relationships between financial and macroeconomic issues.

In order to better understand the link between financial and business cycles, it is first necessary to define the main features of financial and business cycles. Although business cycles are frequently investigated in the literature, the numbers of studies for understanding the properties of financial cycles are not sufficient.

Claessens et al. (2011a) analyzed the frequency, duration, amplitude and slope of financial cycles for 21 advanced OECD countries. Egert and Sutherland (2012) investigated the main characteristics of financial and business cycles and measured the degree of synchronization between these cycles in OECD countries. Borio (2014) and Drehmann et al. (2012) also contributed to the literature by trying to detect the core empirical features of financial cycles for better modeling strategies.

As the main pillars of a financial system, banks and capital markets possibly influence real economic activity. According to Egert and Sutherland (2012), this mechanism works through the bank lending channel and balance sheet channel. Bank credit cycles can move in the same direction as the cycles in the real economy. Hence, this pro-cyclical feature of the banking sector may boost the real cycle.

Asea and Blomberg (1998) provide empirical results for the United States (USA) about the pro-cyclical behavior of bank credits. They report that there is feedback from the real cycle to the bank credits. Schularic and Taylor (2009) show some evidence that the financial system generates an economic instability through endogenous credit booms. Ayuso et al. (2004) indicate that the demand for, and supply of, bank credits oscillates over the cycle, because credit demand is connected with production and investments. Gonzales and Reyes (2011) investigated the bank-firm relationships over the business cycle in Colombia and suggest that the number of bank relationships is counter-cyclical.

The vast numbers of related studies try to provide empirical results for a better understanding of the link between financial and macroeconomic issues. AvouyiDovi and Matheron (2005) investigated the comovements between stock prices, real activity and the interest rate on the business cycle frequency for the USA, France, Germany, the United Kingdom (UK) and Italy. They found no strong relationship between stock prices and the level of real activity in the business cycle frequency in France, Germany, the UK or Italy, but a strong relationship did exist in the USA.

Borio et al. (2013) argued that financial factors play a significant role in the fluctuations of the business cycle. They performed an empirical analysis on data in the USA, UK and Spain and found that for financial cycle information, the behavior of credit and property prices could be used to explain a substantial part of the cyclical movements in output.

$\mathrm{Ng}$ (2011) explored the role of financial cycle measures to forecast the output GDP growth rate and concluded that including financial cycles in the estimation equations promotes the forecasting performance for the short horizons. Christiano et al. (2010) investigated whether financial market shocks affect business cycle fluctuations for Europe and the USA. Their findings show that financial shocks are important factors that explain changes in the macroeconomic variables. 
Gilchrist and Zakrajsek (2009) estimated the dynamic stochastic general equilibrium (DSGE) model by using quarterly data for the USA to determine the significance of the financial factors in the business cycle fluctuations. They suggest that financial disruptions play an important role in declines in output growth. Claessens et al. (2011b) analyzed interactions between business and financial cycles for 44 countries, using extensive quarterly data and they found evidence that there are strong relationships between these cycles.

A substantial part of the empirical studies were devoted to measuring the degree of synchronization between the different cycles. Harding and Pagan (2002a, 2002b, 2006) proposed cycle dating algorithms and a concordance index calculation method to determine the level of synchronization. Candelon et al. (2008) tailored the generalized method of moments (GMM) to measure the cyclical stock market synchronization.

Giannone et al. (2009) and Morgan et al. (2004) developed business cycle synchronization measures. Kang (2011) investigated the lead-lag relationships in international business cycles. Kalemli-Ozcan et al. (2009) tried to explain the effect of financial integration on the degree of business cycle synchronization by using a panel of twenty developed countries. Unlike traditional cross-sectional studies, their results indicated that a higher degree of financial integration leads to less synchronized output cycles.

Claessens et al. (2011a) studied the synchronizations of financial cycles within and across countries. Artis et al. (2011) contributed to the literature by analyzing business cycle co-movements for 25 advanced and emerging economies including Turkey.Avouyi-Dovi and Matheron (2005) measured the concordance between financial and business cycles. Gachter et al. (2012) investigated the business cycle synchronization in the Euro area and analyzed the effect of the global economic crisis in 2008 on the synchronization pattern of business cycle synchronization.

Although numerous papers have been written on the relationship between financial and business cycles, the empirical and theoretical literature has remained scant for the Turkish economy. Duval et al. (2014) examined the effect of trade integration on business cycle synchronization for 63 advanced and emerging economies and suggested that there is a strong positive impact of trade intensity on business cycle synchronization. Akkoyun et al. (2014) analyzed the business cycle synchronization of the Turkish economy with the Euro zone and the USA by using wavelet methodology. They concluded that the correlation between the Turkish-Euro zone and Turkish-USA cycles increased after the 2001 crisis. Since aforementioned studies either estimated the relationship between trade integration and business cycle synchronization or business cycle synchronizations of theTurkish economy and Euro area, they did not concentrate on financial indicators which are quite important for the Turkish economy, especially after the global financial crisis. Additionally, the financial structure of the Turkish economy has changed after the global financial crisis: the share of FDI flows in total capital flows has decreased while the share of the portfolio flows has increased following the global economic crisis in 2008. Therefore, this paper applies the DCC model in order to seize possible synchronizations between financial and business cycles which are important to understanding the structure of the Turkish economy

\section{METHODOLOGY}

\section{Measurement of Business and Financial Cycles}

The main philosophy of measuring any cycle is the elimination of trends from the time series. The cyclical component of any time series can be achieved by subtracting the trend from the variable. Thus, this process allows for keeping only the fluctuations around the trend. In the literature, the most popular filtering methods used to obtain the cyclical components of any time series are the HP filter, the Baxter-King band-pass filter and the Christiano-Fitzgerald band-pass filter (Gachter et al., 2012).

In this study, we tried to obtain the cyclical components of the corresponding variables by using an HP filter. The main idea for selecting the HP filter is the easy usage and comparability of the results between similar studies.

Massman and Mitchell (2004) proposed that the selection of any filtering method does not have any significant effect on the results. That being said, the HP filter removes a trend $\left(\tau_{t}\right)$ from the time series $y_{t}$, where $y_{t}=\tau_{t}+c_{t} \cdot c_{t}$ represents the deviations from the trend, which is the cyclical component of the $y_{t}$. In this 
framework, the trend part of the time series can be determined by solving the following minimization problem (Hodrick and Prescott, 1997).

$$
\underset{\left\{\tau_{t} t_{t=-1}^{n}\right.}{\operatorname{Min}}\left\{\sum_{t=1}^{T} c_{t}^{2}+\lambda \sum_{t=1}^{T}\left[\left(\tau_{t}-\tau_{t-1}\right)-\left(\tau_{t-1}-\tau_{t-2}\right)\right]^{2}\right\}
$$

where: $c_{t}=y_{t}-\tau_{t} \cdot \lambda$ is the smoothing parameter and penalizes the variability in the trend, relative to the cyclical component. In many empirical studies, $\lambda=$ 1600 for quarterly data (Ravn and Uhlig, 2002). ${ }^{2}$

\section{Dating the Turning Points and the Concordance Index}

In previous empirical studies related to business cycles, the turning points of the cycles are dated. The most popular method for performing this task was introduced by Bry and Boschan (BB) (1971). The BB algorithm requires a search for the maximum and minimum points over the investigated period for a monthly series. Harding and Pagan (2002a) tailored the $\mathrm{BB}$ algorithm and developed the quarterly version of the $\mathrm{BB}$ algorithm called the BBQ.

In this study, the BBQ algorithm is used to identify the turning points of the financial and business cycles. According to the BBQ algorithm, the series $y_{t}$ has a local maximum at time $t$, if the following conditions are provided (Claessens et al., 2011a):

$$
\begin{aligned}
& \left\{\left(y_{t}-y_{t-2}\right)>0,\left(y_{t}-y_{t-1}\right)>0\right. \text { and } \\
& \left.\left(y_{t+2}-y_{t}\right)<0,\left(y_{t+1}-y_{t}\right)<0\right\} .
\end{aligned}
$$

By using the same logic, it can be said that local minimum appears at time $t$ if:

$$
\begin{aligned}
& \left\{\left(y_{t}-y_{t-2}\right)<0,\left(y_{t}-y_{t-1}\right)<0\right. \text { and } \\
& \left.\left(y_{t+2}-y_{t}\right)>0,\left(y_{t+1}-y_{t}\right)>0\right\} .
\end{aligned}
$$

After identifying the peak and trough points, the contraction and expansion phases for our variables can easily be defined.

In this study, the concordance index developed by Harding and Pagan (2002a, 2006) is used as a concordance indicator between the business and financial cycles. The concordance index points out the

\footnotetext{
${ }^{2}$ Hodrick and Prescott (1997) provide detailed information about the decomposition procedure of the HP filter and the selection method of the smoothing parameter. They also show how sensitive the results are to the value of the selected smoothing parameter. Ravn and Uhlig (2002) adjust the HP filter for the different frequencies of observations.
}

average number of periods in which two variables $(x$ and $y$ ) concur at the same phase of the cycle. It is calculated as follows (Avouyi-Dovi and Matheron, 2005):

$$
\text { CIxy }=\frac{1}{T} \sum_{t=1}^{T}\left[S_{t}^{x} S_{t}^{y}+\left(1-S_{t}^{x}\right)\left(1-S_{t}^{y}\right)\right]
$$

where:

$$
S_{t}^{x}=\left\{\begin{array}{c}
1, \text { if } x \text { is in expansion at time } t \\
0, \text { otherwise }
\end{array}\right\}
$$

and

$$
S_{t}^{y}=\left\{\begin{array}{c}
1, \text { if } y \text { is in expansion at time } t \\
0, \text { otherwise }
\end{array}\right\}
$$

The concordance index value changes from 0 to 1 . If it is equal to 1 , the investigated variables are always in the same phase. A value of 0 indicates that the variables are always in opposite phases.

\section{Dynamic Conditional Correlations}

The relationships between variables don't remain the same for a long period of time. However, the time varying relationships between the variables may sometimes have more explanatory power (Lebo and Steffensmeier, 2008; Akar, 2011).

One of the most popular models currently used to determine the time varying correlations between the variables is Engle's (2002) DCC model. The DCC model is a typical multivariate generalized auto regressive conditional heteroskedastic (GARCH) model. The main advantage of the DCC model over other multivariate GARCH models is that the number of parameters to be estimated is limited. In practice, some restrictions may be imposed on the model to serve the aim of parameter reducing.

In this study, the following dynamic conditional correlation (DCC) specification of the $M$ dimensional multivariate $\mathrm{GARCH}(1,1)$ model is used to determine the dynamic conditional correlations (Seo et al., 2009):

$$
\begin{aligned}
& Y_{t}=\phi_{0}+\phi_{1} Y_{t-1}+\varepsilon_{t} \varepsilon_{t} \sim N\left(0, H_{t}\right) \\
& H_{t}=\Gamma_{t} R_{t} \Gamma_{t} \\
& \Gamma_{t}=\operatorname{diag}\left\{\sqrt{h_{11, t}}, \sqrt{h_{22, t}}, \cdots \sqrt{h_{M M, t}}\right\} \\
& h_{i i, t}=w_{i}+\beta_{i} h_{i i, t-1}+\gamma_{i} \varepsilon_{i, t-1}^{2} i=1,2 \ldots \ldots M
\end{aligned}
$$


$R_{t}=\left(\operatorname{diag}\left\{Q_{t}\right\}\right)^{-1 / 2} Q_{t}\left(\operatorname{diag}\left\{Q_{t}\right\}\right)^{-1 / 2}$

$Q_{t}=(1-\alpha-\beta) \bar{Q}+\alpha u_{t-1} u_{t-1}^{\prime}+\beta Q_{t-1}$

where: $Y_{t}=\left(Y_{1, t}, Y_{2, t} \ldots, Y_{M, t}\right)^{\prime}$ and $\varepsilon_{t}=\left(\varepsilon_{1, t}, \varepsilon_{2, t} \ldots, \varepsilon_{M, t}\right)$ are $M x 1$ vectors. $H_{t}$ is the conditional covariance matrix of the random vector $\varepsilon_{t}$ and $u_{t}=\left(\varepsilon_{1, t} / \sqrt{h_{11, t}}, \varepsilon_{1, t} / \sqrt{h_{11, t}} \cdots \varepsilon_{i, t} / \sqrt{h_{M M, t}}\right)^{\prime}$ is a vector that contains the standardized values of $\varepsilon_{t} . R_{t}$ is the time varying correlation matrix and $Q_{t}$ is the positive definite symmetric matrix. $\bar{Q}$ represents the unconditional variance matrix of $u_{t} . \alpha$ and $\beta$ are scalars, $\alpha \geq 0, \beta \geq 0$ and $\alpha+\beta<1$, for the positive definiteness of a conditional correlation matrix. The time varying elements of $Y_{t}, \rho_{i j, t}$ are:

$\rho_{i j, t}=\frac{q_{i j, t}}{\sqrt{q_{i i, t} q_{j j, t}}}$

where: $q_{i j, t}$ is the $i$-j th element of $Q_{t}$. To estimate the unknown parameters, the following likelihood function is maximized by applying iterative numerical techniques:

$L(\theta)=-\frac{1}{2} \sum_{t=1}^{T}\left(M \log (2 \pi)+2 \log \left(\left|\Gamma_{t}\right|\right)+\log \left(\left|R_{t}\right|\right)+u_{t}^{\prime} R_{t}^{-1} u_{t}\right)$

where $\mathrm{T}$ is the number of observations and $M$ is the number of the variables in the system; $\theta$ denotes all parameters to be estimated in the system.

\section{DATA AND EMPIRICAL RESULTS}

The data used in the study includes real quarterly GDP, household consumption, total credit volume and the BIST -100 index series for Turkey. The dataset extends from 1998Q1 to 2014Q4 and was gathered by the Central Bank of the Republic in Turkey by means of an electronic data delivery system. We use GDP and household consumption to study the business cycle. These variables are common measures used to track the total economic activity in empirical studies. For financial cycles, we use two variables: the total credit volume on the private sector by the deposit money banks and the BIST-100 Index. All variables are seasonally adjusted and logarithmic growth rates of them are used in the empirical analysis. The summary statistics of the seasonally adjusted growth rates of the variables reported in Table 1.

The first step of the empirical analysis is to obtain the cyclical components of the investigated variables. After applying the HP filter, the cycles are obtained (Figure 1). Figure 1 also illustrates the turning points for the expansion and recession periods.

In the second step of the analysis, the concordance index value of the cycles is calculated according to the aforementioned procedure. The concordance index matrix is presented in Table 2 . The degree of synchronization between the cycles varies from 0.529 to 0.824 . As we expected, the synchronization between GDP and the household consumption cycles is high. The concordance index value of 0.824 indicates that 82.4 percent of the time, these two cycles are in the same phase. On the other hand, the lowest concordance index is 0.529 ; this was observed for cycles between the credit volume and BIST-100.

To determine the synchronization between the business and financial cycles, it is necessary to evaluate the concordance index value of the cycles GDP-Credit volume, GDP-BIST-100, household consumption-credit volume and household consumption-BIST100. These values are $0.765,0.647$, 0.618 and 0.706 , respectively. These results imply that the GDP cycle and credit volume cycles are highly synchronized. The other values also imply that the synchronization degree between the financial and business cycles is high. Hence, it can be concluded that average 68.4 percent of the time, business and financial cycles are in the same phase.

The third step of the study attempted to understand the lead-lag relationships of the financial and business cycles. Table 3 presents the cross-correlation matrix of

Table 1: Summary Statistics for Seasonally Adjusted Growth Rates of the Variables

\begin{tabular}{|c|c|c|c|c|}
\hline & GDP & Consumption & BIST & Credit \\
\hline \hline Mean & 0.865719 & 0.865812 & 4.814116 & 7.157205 \\
\hline Median & 1.078291 & 1.027412 & 4.452404 & 7.214957 \\
\hline Standard Deviation & 2.287933 & 2.371286 & 17.68851 & 5.133409 \\
\hline Skewness & -0.840972 & -0.328269 & 0.251105 & -0.344815 \\
\hline Kurtosis & 3.725269 & 2.797611 & 4.290067 & 3.642008 \\
\hline
\end{tabular}


(a) GDP

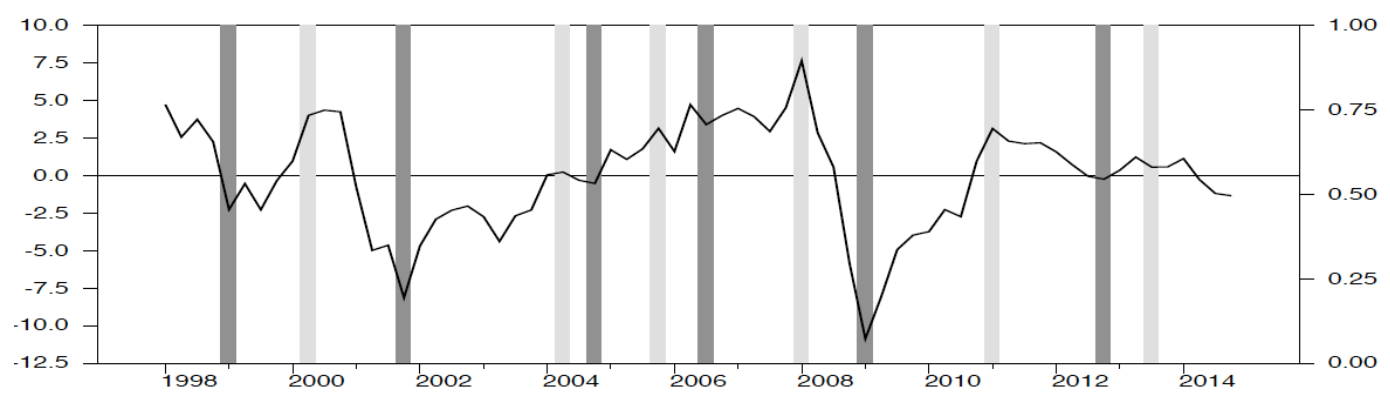

(b) Household Consumption

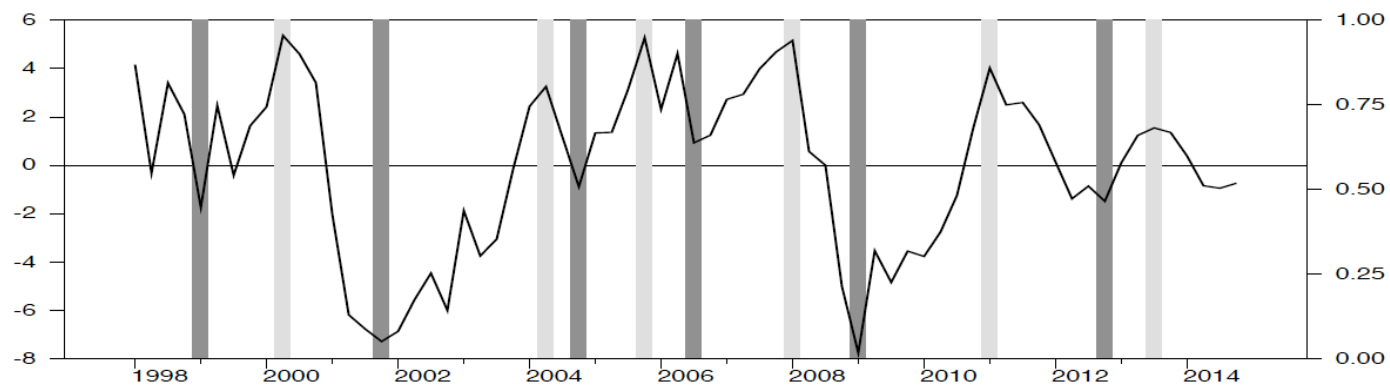

(c) Credit Volume

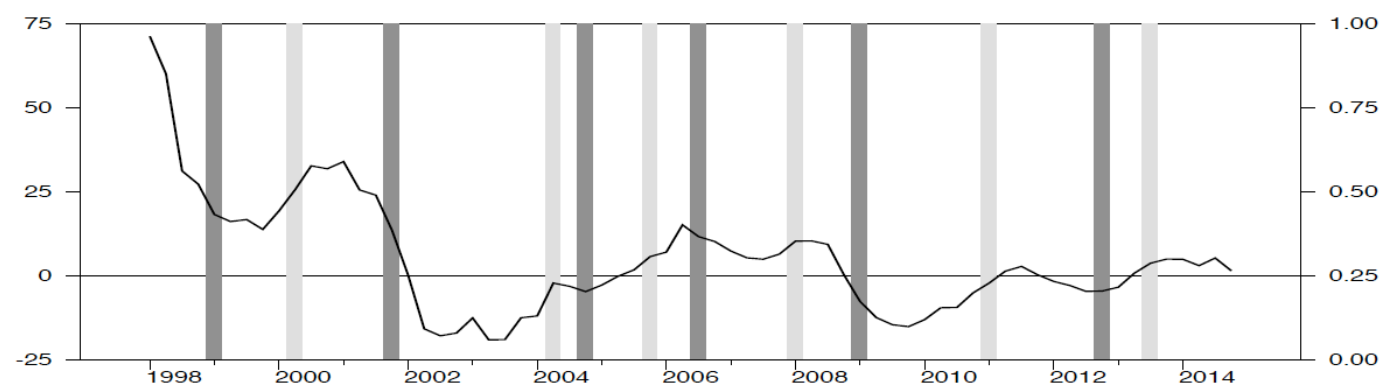

(d) BIST100

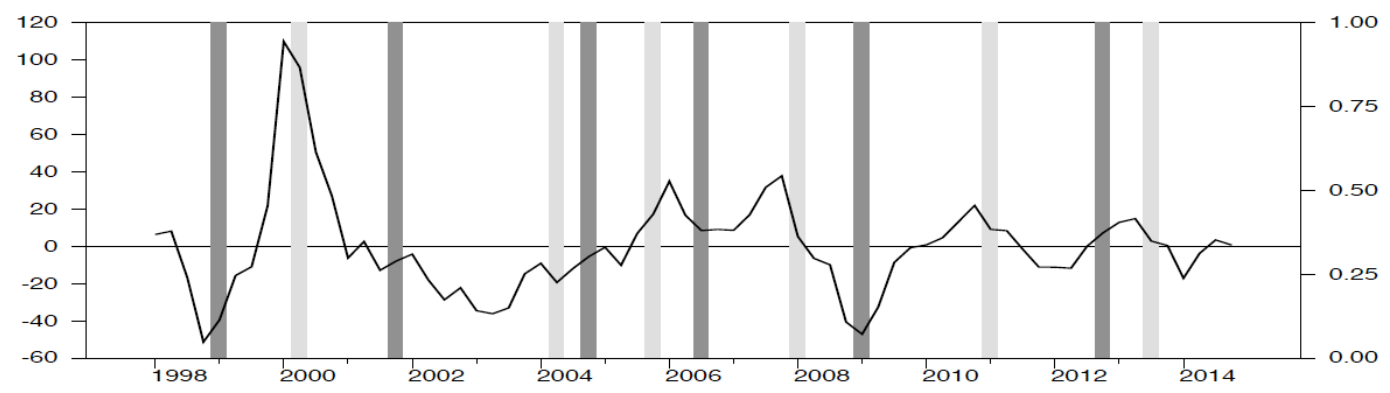

Figure 1: Turning Points of the Business and Financial Cycles in Turkey.

the business and financial cycles. GDP and the household consumption cycles were found to be strongly and positively correlated at the lag of $-1,0$ and 1.

If we look at the cross-correlations between the GDP cycle and credit volume cycle, the cross correlations values of the lags $-3,-2$ and -1 are 0.440 , 0.474 , and 0.483 respectively. These findings show that the GDP cycle lags from the credit volume cycle. In other words, the credit volume cycle is the leading factor of the GDP cycle.

The cross-correlation values for the GDP and BIST 100 cycles are 0.626 and 0.519 at lags 1 and 2, respectively, indicating that the GDP cycle leads from the BIST 100 cycle. 
Table 2: Concordance Index Matrix

\begin{tabular}{|c|c|c|c|c|}
\hline & GDP & Consumption & Credit & BIST100 \\
\hline \hline GDP & 1 & & & \\
\hline Consumption & $0.824^{*}$ & 1 & & \\
\hline Credit & $0.765^{*}$ & $0.618^{*}$ & 1 & 1 \\
\hline BIST100 & $0.647^{*}$ & $0.706^{*}$ & $0.529^{*}$ & \\
\hline
\end{tabular}

*significant at the $5 \%$ level.

Table 3: Cross-Correlation Matrix of the Business and Financial Cycles

\begin{tabular}{|c|c|c|c|c|c|c|c|}
\hline & \multicolumn{7}{|c|}{$\mathrm{GDP}_{t-p}$} \\
\hline$p$ & -3 & -2 & -1 & 0 & 1 & 2 & 3 \\
\hline Consumption & $0.247^{*}$ & $0.476^{*}$ & $0.666^{*}$ & $0.890^{*}$ & $0.780^{*}$ & $0.621^{*}$ & $0.385^{\star}$ \\
\hline Credit & $0.440^{*}$ & $0.474^{*}$ & $0.483^{*}$ & $0.430^{*}$ & $0.241^{*}$ & 0.098 & -0.081 \\
\hline \multirow[t]{2}{*}{ BIST100 } & -0.026 & 0.110 & 0.289 & $0.499^{*}$ & $0.626^{*}$ & $0.519^{*}$ & 0.316 \\
\hline & \multicolumn{7}{|c|}{ Consumption $_{t-p}$} \\
\hline$p$ & -3 & -2 & -1 & 0 & 1 & 2 & 3 \\
\hline Credit & $0.516^{*}$ & $0.505^{\star}$ & $0.469^{*}$ & $0.364^{*}$ & 0.145 & 0.026 & -0.152 \\
\hline \multirow[t]{2}{*}{ BIST100 } & 0.155 & 0.264 & 0.396 & $0.524^{*}$ & $0.560^{*}$ & $0.473^{*}$ & 0.129 \\
\hline & \multicolumn{7}{|c|}{ Credit $_{t-p}$} \\
\hline$p$ & -3 & -2 & -1 & 0 & 1 & 2 & 3 \\
\hline BIST & -0.065 & 0.005 & 0.167 & $0.316^{*}$ & $0.430^{*}$ & $0.474^{*}$ & $0.458^{*}$ \\
\hline
\end{tabular}

*significant at the $5 \%$ level.

If we take the household consumption cycle as a business cycle, instead of the GDP cycle, the findings remain unchanged. The sign and the magnitude of the cross-correlation values for household consumptioncredit volume and household consumption -BIST100 cycles are parallel with the GDP cycle. The crosscorrelation values between the credit volume and BIST100 cycles are 0.430 and 0.470 at lags 1 and 2 , which suggest that the credit volume cycle leads from the BIST100 cycle.

The last step of the empirical analysis was devoted to the dynamic conditional correlations. According to the estimation results of the DCC model, the dynamic conditional correlations of the investigated cycles are shown in Figure 2. ${ }^{3}$ The GDP cycle and the household consumption cycle relationship in the examined period are positive and strong. The strength of the relationship showed an increasing pattern between the 2003Q1 and the 2008Q4, with a $0.78-0.80$ correlation coefficient.

\footnotetext{
${ }^{3}$ The estimation results of the DCC model are not reported to save space. Instead, the conditional correlation graphs are presented to analyze the dynamic relationships between investigated cycles.
}

The relationship between the GDP and credit volume cycles was also positive. The strength of the correlation was comparatively low until the 2001Q1. After this date, the relationship demonstrated an increasing trend until the end of 2008. The correlation coefficient during this period reached 0.75 . At the break at the end of 2008 , the step back was the correlation coefficient of 0.65 ; it almost remained at the same level until the end of the investigated period. A similar structure was observed in the relationship between household consumption and the credit cycles.

If we analyze the dynamic conditional correlations between GDP-BIST100, household consumptionBIST100 and the credit volume-BIST100 cycles, we observe a weak relationship with a correlation coefficient between 0.10-0.40 until the end of 2008 . After 2008, even this weak relationship was broken and the correlations were reduced to almost 0.10 levels.

A most significant condition observed in Figure $\mathbf{2}$ is the effect on the relationships between the cycles of the 2008 global crisis. The global crisis was one of the most important break points in the relationships of the 
(a)

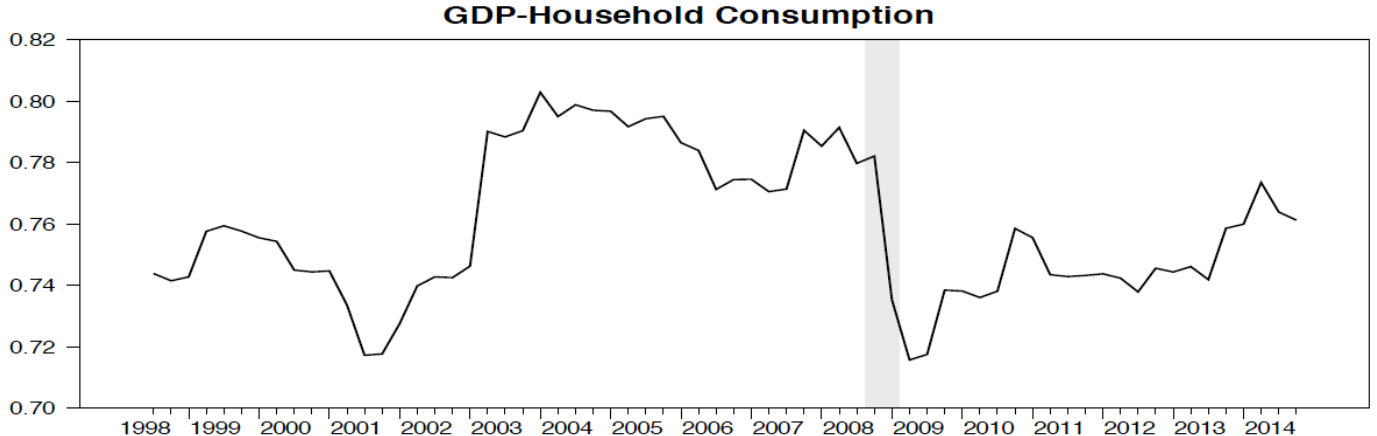

(b)

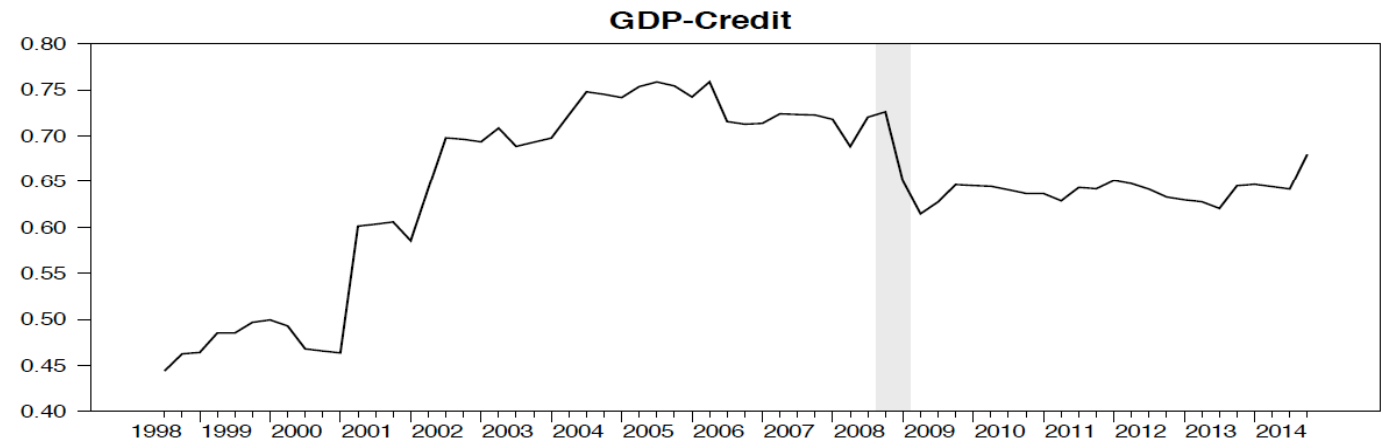

(c)

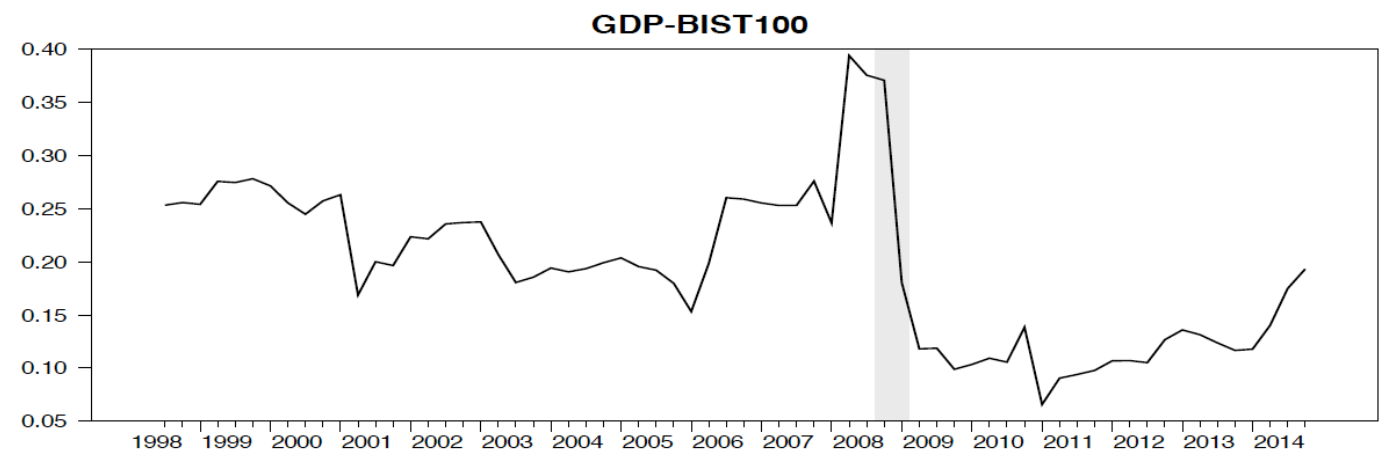

(d)

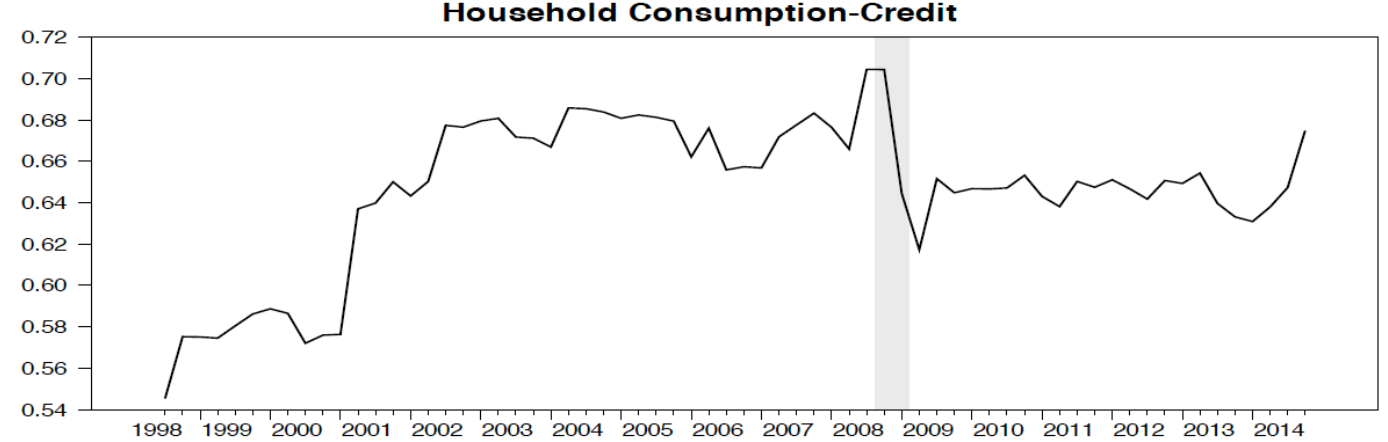


(e)

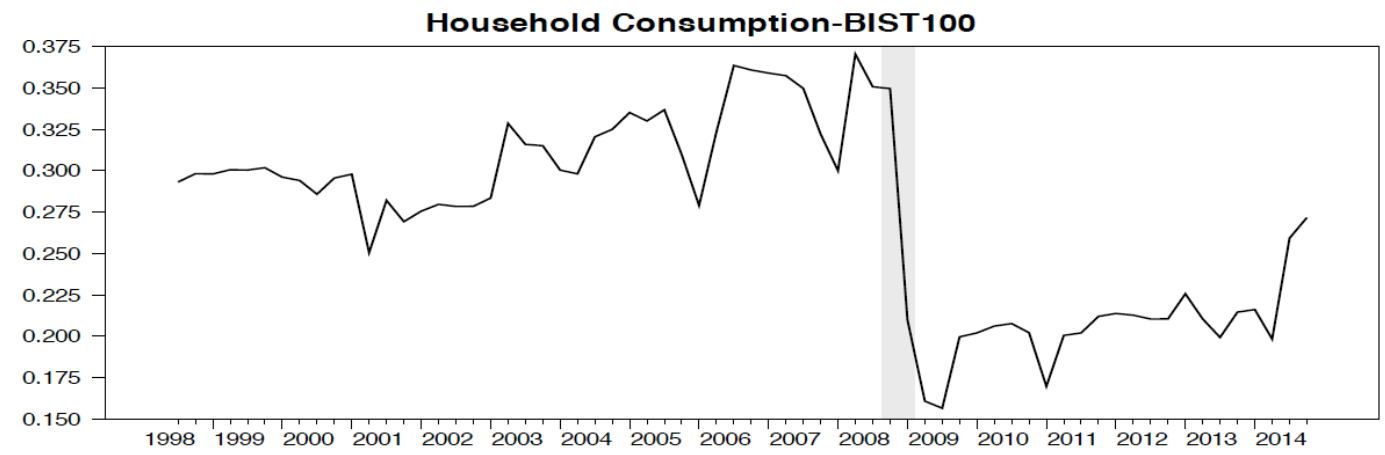

(f)

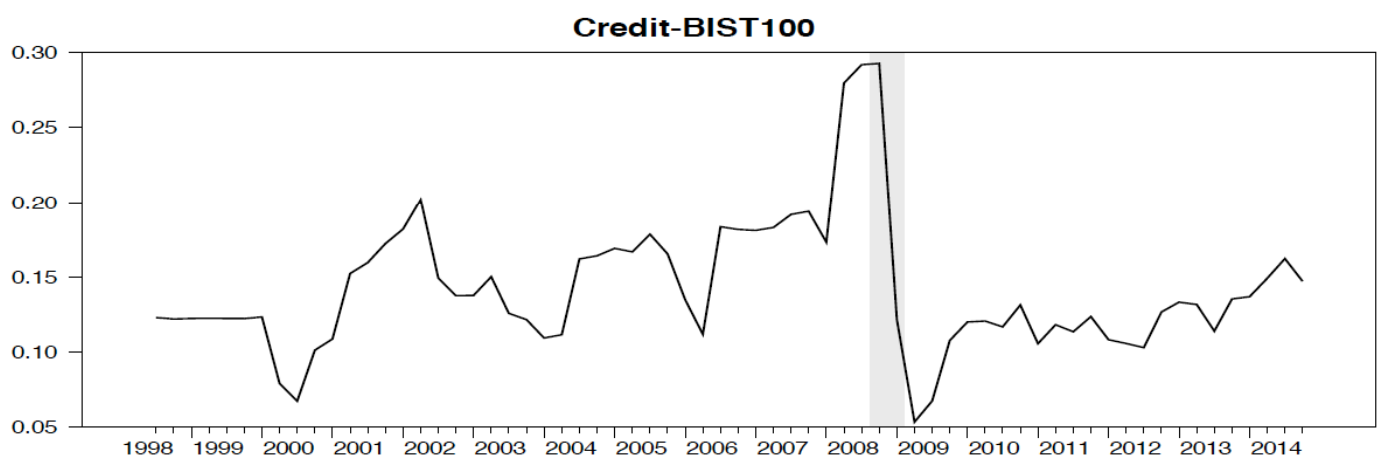

Figure 2: Dynamic Conditional Correlations.

business and financial cycles. The significant point which we shouldpay attention to here is that the correlations between all of the cycles decreased after the crisis period. In other words, the relationships among the cycles broke after the crisis period.

The results from the findings imply that the relationship between credit cycle and the real business cycle had been improved especially since the global financial crisis. There are two reasons behind this result. The first one is that the Central Bank of the Republic of Turkey (CBRT) started to implement a different monetary policy just following the global financial crisis in order to secure financial stability in addition to price stability. They constantly started to monitor and affect the credit volume and this variable became one of the most important variables for achieving monetary stability. The second one is that the structure of the capital movements has changed toward to the emerging economies as well as to Turkey. Before theglobal financial crisis, the share of the FDI flows was higher in total capital flows in Turkey. But after the crisis, the share of the FDI has decreased since the speed of privatization has decelerated, political tensions has increased, among others. Since it is more likely that the FDI flows may increase credit volume by decreasing interest rates (by expanding the credit facilities), we can provide an explanation to softening the relationship between credit cycle and the real business cycle since the global financial crisis.

After the global financial crisis, the share of the portfolio investments in total capital flows has raised in Turkey, especially since 2009. Since it is clear that this kind of speculative movements will tend to awillingness to have more returns in the short-run, they will pour in BIST rather than banking sector. Hence, there emerges negative relationship between credit volume cycle and BIST 100 cycle in the periods speculative flows are higher than FDI flows.

\section{CONCLUSIONS}

A significant feature of recessions, faced by both advanced and emerging economies, is that they generally appear after financial disturbances, such as decreasing asset prices. The key role of financial issues on recession problems has been discussed intensively in the literature during the last decade. The studies are mostly oriented to the relationships 
between business and financial cycles. These relationships may be more important for emerging economies, due to the possibility of a deeper effect of recessions, than for advanced economies.

In this study, we analyzed the interaction between business and financial cycles in Turkey, an important emerging economy. Quarterly Turkish data used in this paper includes GDP, household consumption, credit volume and BIST 100 index variables in the sampling period from 1998Q1 to 2014Q4. We used the HP filter to obtain business and financial cycles. To investigate the link between business and financial cycles, we calculated the concordance index values and the cross-correlations. We also analyzed the time varying dynamic conditional correlations by using the DCC model.

Our findings highlight three main conclusions. First, the synchronization degree between financial and business cycles in Turkey is high. The empirical results suggest that average 68.4 percent of the time, business and financial cycles are in the same phase. Second, according to the cross-correlation coefficients, the credit volume cycle is the leading factor of the GDP cycle. In addition, the GDP cycle leads from the BIST 100 cycle. Third, the time varying conditional correlations show that the relationship between the GDP cycle and the credit volume cycle is positive and strong. A similar condition was observed for the household consumption and credit volume cycle.

The results also revealed that the dynamic conditional correlations for GDP-BIST100 and the household consumption-BIST100 cycles existed, which indicates that the relationship between these cycles is weak. The global crisis that occurred at the end of 2008 was found to be the most important break point for the time varying relationships. After this date, the dynamic conditional correlations suddenly decreased and followed a more stable pattern, until the end of the investigated period.

The results have significant policy implications. They are consistent with the view that financial disruptions have a great potential to deepen recessions. Therefore, policy-makers who try to reach goals related to the real economy should take financial cycles into account. If the authorities responsible for growth and price stability don't consider the financial cycles, they may be successful in the short run, but it may lead to larger recessions. Drehman et al. (2012) called this phenomenon an "unfinished recession".
We recommend that future studies address issues about the duration and amplitude of financial and business cycles for emerging economies. This kind of study design may help to identify the possible timing of a future crisis, which can cause serious damage to emerging economies.

\section{REFERENCES}

Adrian, T.; Estrella, A.; Shin, H. S., 2010. "Monetary Cycles, Financial Cycles, and the Business Cycle."Staff Report Federal Reserve Bank of New York 421:1-18. http://dx.doi.org/10.2139/ssrn.1532309

Akar, C. 2011."Dynamic Relationships between the Stock Exchange, Gold and Foreign Exchange Returns in Turkey." Middle Eastern Finance and Economics12:109-114.

Akkoyun H., Ç., Doğan, Ş.B. and Günay, M., 2014. "Business Cycle Synchronization of Turkey with the Eurozone and the United States: What Has Changed Since 2001?" Emerging Markets Finance and Trade. 50(4):26-41. http://dx.doi.org/10.2753/REE1540-496X500402

Artis, M., Chouliarakis, G. and Harischandra, P., 2011. "Business Cycle Synchronization since 1880." Manchester School, 79(2): 173-207.

http://dx.doi.org/10.1111/j.1467-9957.2010.02239.x

Asea, P.K. and Blomberg, B., 1998." Lending Cycles." Journal of Econometrics. 83: 89-128. http://dx.doi.org/10.1016/S0304-4076(97)00066-3

Avouyi-Dovi, S. and Matheron, J., 2005." Interactions between Business Cycles, Financial Cycles and Monetary Policy: Stylised Facts." BIS Papers 22: 273-298.

Ayuso, J., D. Pérez and Saurina, J., 2004. "Are Capital Buffers Procyclical? Evidence from Spanish Panel Data." Journal of Financial Intermediation 13:249-264. http://dx.doi.org/10.1016/S1042-9573(03)00044-5

Besomi, D., 2006. "Tendency to Equilibrium, the Possibility of Crisis, and the History of Business Cycle Theories." History of Economic Ideas 14 (2): 53-104.

Borio, C., Disyatat, P., and Juselius, M., 2013." Rethinking Potential Output: Embedding Information from the Financial Cycle." BIS Working Paper. February 404:1-29.

Borio, C., 2014. "The financial cycles and macroeconomics: What have we learnt?" Journal of Banking \& Finance. 45:182-198. http://dx.doi.org/10.1016/j.jbankfin.2013.07.031

Bry, G. and Boschan, C. 1971. "Cyclical analysis of time series: selected procedures and computer Programs.", NBER Books. New York, Columbia University Press.

Burns, A. and Mitchell, W.C., 1946. "Measuring Business Cycles. National Bureau of Economic Research", New York. NBER Inc.

Candelon, B., Piplack, J., \& Straetmans, S., 2008. "On Measuring Synchronization of Bulls and Bears: The Case of East Asia." Journal of Banking \& Finance, 32(6): 1022-1035. http://dx.doi.org/10.1016/j.jbankfin.2007.08.003

Christiano, L. J., Motto, R., and Rostagno, M., 2010. "Financial Factors in Economic Fluctuations." European Central Bank Working paper Series 1192: 1-91.

Claessens, S., Kose, M.A., and Terrones, M.E., 2011a. "Financial Cycles: What? How? When?" IMF Working Paper. WP/11/76: 1-36.

Claessens, S., Kose, M.A., and Terrones, M.E., 2011b. "How Do Business and Financial Cycles Interact? "IMF Working Paper WP/11/88:1-54.

Claessens, S., Kose, M.A., Terrones, M.E., 2012. "How Do Business and Financial Cycles Interact?" Journal of International Economics. 87: 178-190. http://dx.doi.org/10.1016/i.jinteco.2011.11.008 
Drehmann, M., Borio, C. E., \& Tsatsaronis, K., 2012. "Characterizing the Financial Cycle: Don't Lose Sight of the Medium Term." BIS Working Papers 380:1-31.

Duval, M. R. A., Cheng, M. K. C., Oh, K. H., Saraf, R., and Seneviratne, M. D. , 2014. "Trade Integration and Business Cycle Synchronization: A Reappraisal with Focus on Asia." IMF Working Paper WP/14/52:1-45.

Egert, B. and Sutherland, D., 2012. "The Nature of Financial and Real Business Cycles: The Great Moderation and Banking Sector Pro-Cyclicality," OECD Economics Department Working Papers 938:1-40.

Engle, R.F., 2002. "Dynamic Conditional Correlation: A New Simple Class of Multivariate GARCH Models." Journal of Business and Economic Statistics. 20: 339-350. http://dx.doi.org/10.1198/073500102288618487

Fisher, I., 1933. "The Debt-Deflation Theory of the Great Depressions". Econometrica 1: 337-357. http://dx.doi.org/10.2307/1907327

Gächter, M., Riedl, A., and Ritzberger-Grünwald, D., 2012. "Business Cycle Synchronization in the Euro Area and the Impact of the Financial Crisis." Monetary Policy \& the Economy, 2: 33-60.

Giannone, D., M. Lenza and L. Reichlin. 2009. "Business Cycles in the Euro Area." Working Paper series. February 1010:1-37.

Gilchrist, S, Yankov V and Zakrajsek, E., 2009. "Credit Market Shocks and Economic Fluctuations: Evidence from Corporate Bond and Stock Markets." Journal of Monetary Economics. 56(4): 471-93. http://dx.doi.org/10.1016/j.jmoneco.2009.03.017

Gonzales, J.E.G. and Reyes, N.R., 2011. "The Number of Banking Relationships and the Business Cycle: New evidence from Colombia." Economic Systems, 35 (3): 408-418. http://dx.doi.org/10.1016/j.ecosys.2010.09.007

Harding, D. and Pagan, P., 2002a, "Dissecting the Cycle: A Methodological Investigation," Journal of Monetary Economics, 49:365-81. http://dx.doi.org/10.1016/S0304-3932(01)00108-8

Harding, D. and Pagan, A., 2002b. "A Comparison of two Business Cycle Dating Methods." Journal of Economic Dynamics and Control 27: 1681-1690. http://dx.doi.org/10.1016/S0165-1889(02)00076-3

Harding, D. and Pagan, A., 2006. "Synchronisation of Cycles." Journal of Econometrics, 132:59-79. http://dx.doi.org/10.1016/j.jeconom.2005.01.023
Hodrick, R.J., Prescott, E.C., 1997. "Postwar U.S. Business Cycles: an Empirical Investigation." Journal of Money Credit and Banking. 29 (1): 1-16. http://dx.doi.org/10.2307/2953682

Kalemli-Özcan, Ş. Papaioannou, E. and Peydro, J.L. 2009. "Financial Integration and Business Cycle Synchronization." CEPR Discussion Paper DP7292: 1-12.

Kang, M., 2011. Leading and lagging relationship in international business cycles, Mimeo, Fudan University. 1-47.

Keynes, J. M., 1936. The general theory of employment interest and money. Moggridge, D.E. (Ed.), Vol. VII, The Collected Writings of John Maynard Keynes (1973).

Lebo, J.M. and Steffensmeier, J.M., 2008. "Dynamic Conditional Correlation in Political Science." American Journal of Political Science 52(3): 688-704. http://dx.doi.org/10.1111/j.1540-5907.2008.00337.x

Massmann, M. and Mitchell. J., 2004. "Reconsidering the Evidence: Are Eurozone Business Cycles Converging?"Journal of Business Cycle Measurement and Analysis. 1(3): 275-308.

Morgan, D. P., Rime, B. and Strahan, P. E., 2004. "Bank Integration and State Business Cycles." Quarterly Journal of Economics, 119(3): 1555-1585. http://dx.doi.org/10.1162/0033553042476161

$\mathrm{Ng}, \mathrm{T} ., 2$ 2011. "The Predictive Content of Financial Cycle Measures for Output Fluctuations." BIS Quarterly Review. June:53-65.

Ravn, M. O., and Uhlig, H. 2002. "On Adjusting the Hodrick-Prescott Filter for the Frequency of Observations." Review of Economics and Statistics, 84(2): 371-376. http://dx.doi.org/10.1162/003465302317411604

Schularick, M. and Taylor, A.M., 2009. "Credit Booms Gone Bust: Monetary Policy, Leverage Cycles and Financial Crises 1870-2008." NBER Working Papers 15512:1-36.

Taban, S., 2011. "Küresel Finans Krizi Öncesive Sonrası Dönemde Türkiye'de Ekonomik Büyümenin Dinamikleri." SETA Analiz, 37:1-33.

Woodford, M., 2010.Globalization and monetary control. Galí, J., Gertler, M. (Eds.), International Dimensions of Monetary Policy, NBER Conference Volume. University of Chicago Press, Chicago. http://dx.doi.org/10.7208/chicago/9780226278872.003.0002

Received on 24-03-2016

Accepted on 20-04-2016

Published on 26-04-2016

\section{DOI: http://dx.doi.org/10.6000/1929-7092.2016.05.03}

(c) 2016 Cüneyt Akar; Licensee Lifescience Global.

This is an open access article licensed under the terms of the Creative Commons Attribution Non-Commercial License (http://creativecommons.org/licenses/by-nc/3.0/) which permits unrestricted, non-commercial use, distribution and reproduction in any medium, provided the work is properly cited. 